\title{
On the use of vibrational spectroscopy and scanning electron microscopy to study phenolic extractability of cooperage byproducts in wine
}

\author{
Berta Baca-Bocanegra \\ Universidad de Sevilla \\ Julio Nogales-Bueno \\ Universidad de Sevilla \\ Brian Gorey \\ Technological University Dublin
}

See next page for additional authors

Follow this and additional works at: https://arrow.tudublin.ie/nanolart

Part of the Food Science Commons, and the Materials Chemistry Commons

\section{Recommended Citation}

Baca-Bocanegra, B., Nogales-Bueno, J., Gorey, B. et al. On the use of vibrational spectroscopy and scanning electron microscopy to study phenolic extractability of cooperage byproducts in wine. Eur Food Res Technol 245, 2209-2220 (2019). DOI: 10.1007/s00217-019-03329-6

This Article is brought to you for free and open access by the NanoLab at ARROW@TU Dublin. It has been accepted for inclusion in Articles by an authorized administrator of ARROW@TU Dublin. For more information, please contact arrow.admin@tudublin.ie, aisling.coyne@tudublin.ie,gerard.connolly@tudublin.ie.

Funder: Spanish MINECO; Universidad de Sevilla 


\section{Authors}

Berta Baca-Bocanegra, Julio Nogales-Bueno, Brian Gorey, Francisco José Heredia, Hugh Byrne, and José Miguel Hernández-Hierro 


\title{
On the use of vibrational spectroscopy and scanning electron microscopy to study phenolic extractability of cooperage byproducts in wine
}

\author{
Berta Baca-Bocanegra ${ }^{1} \cdot$ Julio Nogales-Bueno ${ }^{1} \cdot$ Brian Gorey $^{2} \cdot$ Francisco José Heredia $^{1} \cdot$ Hugh J. Byrne $^{2}$. \\ José Miguel Hernández-Hierro ${ }^{1}$
}

Received: 13 May 2019 / Revised: 27 June 2019 / Accepted: 29 June 2019 / Published online: 11 July 2019

(c) Springer-Verlag GmbH Germany, part of Springer Nature 2019

\begin{abstract}
Wood is an important source of phenolic compounds, which can be transferred to wine during aging process, improving its properties, from an organoleptic point of view. Therefore, understanding and optimizing the extractability of phenolic compounds from wood are crucial in the oenological field. The structural composition of oak wood samples has been evaluated using Raman and attenuated total reflectance Fourier transform infrared (ATR-FTIR) spectroscopies, and their main spectral features have been linked to phenolic compound extractabilities, as measured by classic chemical analyses. To support the analysis, microscopic images of the samples were also recorded using scanning electron microscopy (SEM). The applied methodology is shown to be useful to relate the wood cell wall structure to phenolic extractability levels of wood samples. It could assist in selecting oak wood suited for improving wine quality with regard to its color or/and stability through the addiction of external copigments to wine.
\end{abstract}

Keywords Red wine $\cdot$ Oak wood $\cdot$ Phenolic extractability $\cdot$ Vibrational spectroscopy $\cdot$ Scanning electron microscopy

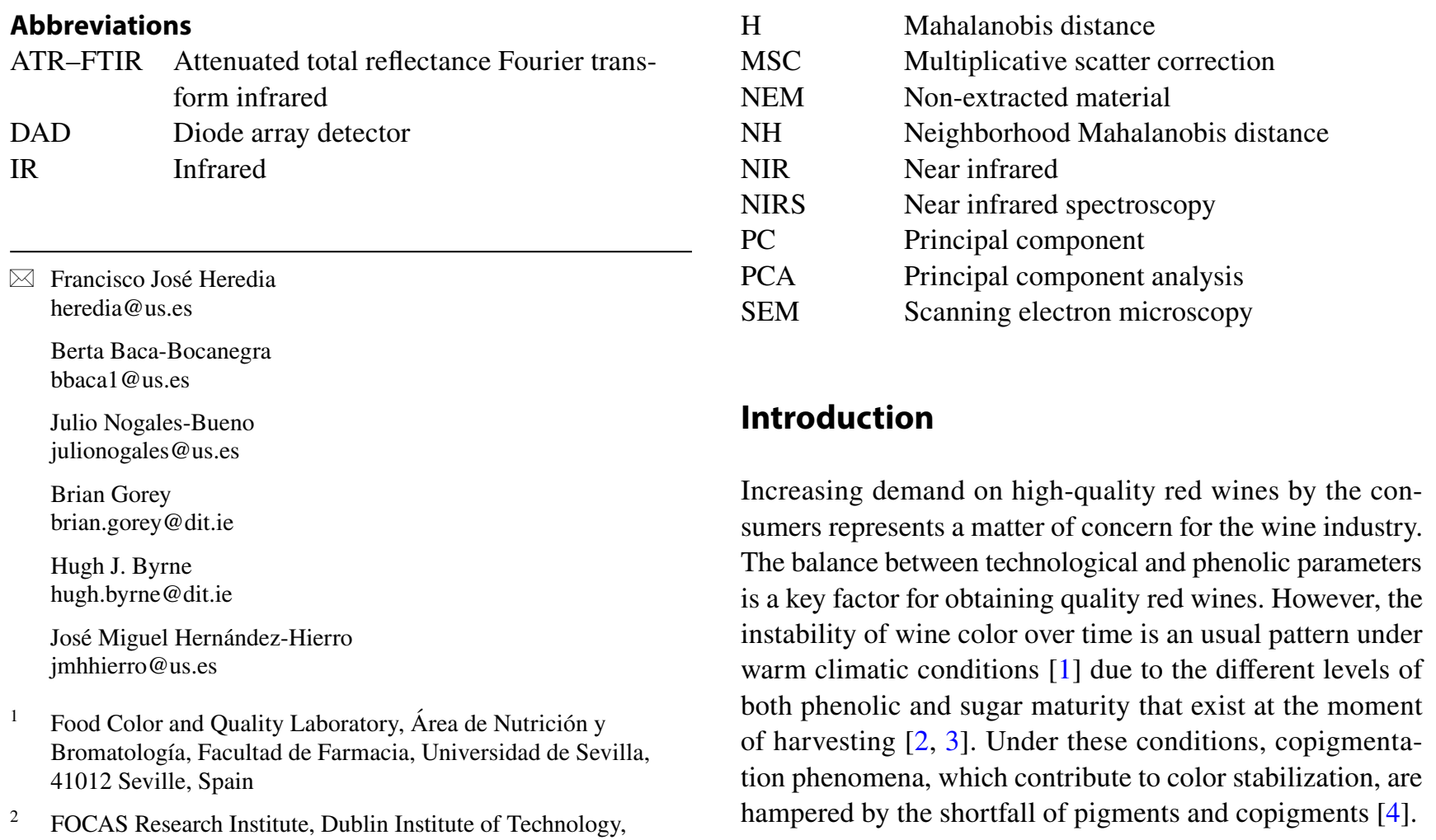


Wood is an important source of phenolic compounds, which can be transferred to wine during the aging process, improving its properties, from an organoleptic point of view (color, astringency, bitterness). In view of this, oak barrels and their alternatives are widely used in winemaking as a source of copigments to achieve high-quality red wines $[5,6]$. In detail, the use of by-products generated during the process of elaboration of barrel is an interesting procedure in the oenological field due to its potential capacity of releasing high-added value compounds for wine and the waste reduction and by-product valorization that this involve.

Phenolic compounds are an important group of substances in the plant kingdom. However, despite their significance, these compounds are part of the so-called extractable fraction that represents only a low percentage of oak wood composition, being cellulose, hemicelluloses and lignin the major constituents $[7,8]$ and the structural basis of wood cell wall.

The characteristics of wines that have been macerated with wood depend not only on the amount of phenolic compounds in the wood but also on the amount of these compounds that can be extracted from the wood to the wine. Factors such as oak species or geographic origin have been shown to affect the chemical composition of the oak wood [9-11], and even different anatomical parts of wood may differ in terms of concentration and composition [12]. Moreover, phenolic content has been found to vary even from the same provenance, the same tree and the same piece of timber [13]. There are evidences that link phenol extractability to chemical composition of wine. For instance, the amount of extracted phenolic compounds from grape skins is related with soluble solids content of grape must [14-19]. In addition, different percentages of ethanol in the medium modify the phenolic extraction rates [20]. The extraction of compounds from wood, especially those of low molecular weight, also depends on the quantity of compounds that are potentially extractable, on the contact time between the wine and wood, as well as on the processing of wood to be used in winemaking (how the staves are obtained, the method of seasoning, chemical treatments and the degree of oak toasting). Extractable compounds in wood can be found interlaced with the cell wall polymers either as inclusions in the cell lumens. Taking that into account, the cell wall structure of wood could affect the easy/difficulty of extraction, that is to say, the wood phenolic extractability. In view of this, it is important to evaluate and understand the relationship between cell wall structure and the extraction degree of phenolic compounds, that is to say, how wood structure and/ or morphology changes within different levels of phenolic compounds extractability. It could assist in selecting oak wood suited for improving wine quality through the addiction of external copigments to wine.
Vibrational spectroscopic techniques, both infrared (IR) and Raman, are powerful analytical tools for materials characterization. As the vibrational energy levels of each molecule correspond to a specific pattern of stretching and bending motions, the infrared and Raman spectra offer a characteristic fingerprint of the molecule [21]. Although both techniques provide chemical information based on molecular vibrational motions, they show different molecular responses, and so complement each other. Thus, it is possible to evaluate the structure of compounds at the molecular level using these two different physical processes [22].

In recent years, infrared spectroscopy has been demonstrated to be a very effective tool in the analysis of wood. Near infrared (NIR) spectroscopy, coupled with chemometric data analysis techniques, has emerged as a powerful technique for the screening of different chemical and physical wood parameters, without the need of time consuming analysis. In this sense, near infrared spectroscopy has been successful in developing calibration models for estimating total and extractable phenolic content in oak wood [23-26]. However, NIR spectra contain information arising from overtones and combinations of fundamental vibrations which result in broad and unresolved bands that make it difficult to interpret the relationship between cell wall composition and phenolic compound extractability. By comparison, mid-IR spectra, commonly measured in the Fourier transform (FT) mode, present sharp and narrow peaks, essentially related to fundamental molecular vibrational frequencies which can be easily assigned to chemical structures [27].

The potential of FTIR spectroscopy to elucidate structural and compositional information of cell wall of wood has been widely investigated in different fields [28-30].

Raman spectroscopy similarly provides a chemical fingerprint of the sample, based on the inelastic scattering of light, by vibrations, and has also been employed to study cell wall structure of wood. An interesting area of Raman application is the identification of wood species and wood origin [31,32]. Moreover, hard and softwoods have been differentiated by FT-Raman and FTIR spectroscopy [33]. Raman imaging spectroscopy has been used to elucidate the spatial distribution of wood constituents, especially the cellulose and lignin [34, 35].

Notably, however, although both mid-infrared and Raman spectroscopy have proven to be useful and reliable techniques for the study of the cell wall structure in wood, they have not yet been applied to study the relationship between cell wall composition and phenolic compounds extractability in wood. In the oenological field, they have been jointly employed to look at extractability from grape skins and seeds [36, 37].

In the present study, the extractability of phenolic compounds has been determined for oak wood samples, selected based in an initial near infrared reflection screening protocol 
[26] and the structural composition of these samples has been evaluated using Raman and attenuated total reflectance Fourier transform infrared (ATR-FTIR). The aim of this study is to evaluate the relationship between the extractability of phenolic compounds from oak wood and the presence of certain chemical structures or families of compounds in the cellular material of these samples. To support this aim, the ATR-FTIR spectral images of the samples were also recorded and scanning electron microscopy (SEM) techniques were also used. The aforementioned information could assist not only in selecting oak wood suited for improving wine quality through the addiction of external copigments to wine, but also to deeply understand the phenolic extraction process from wood to wine.

\section{Materials and methods}

\section{Samples and sample selection}

American non-toasted oak (Quercus alba L.) shavings, provided by Tonelería Salas S.L. (Bollullos Par del Condado, Huelva, Spain), were collected for this study, as previously reported by Baca-Bocanegra et al. [23]. Briefly, raw wood samples were obtained by processes of sawing the staves in the longitudinal and transversal direction of the fibers. Therefore, two groups of samples were obtained, a longitudinal set and a transversal one. In all, two hundred samples were collected (150 longitudinal and 50 transversal). Upon receipt, the samples were sieved and subjected to a near infrared spectral analysis as previously described elsewhere in Baca-Bocanegra et al. [26]. An unsupervised pattern recognition technique, principal component analysis (PCA), was used to select representative samples from the spectral data set to reduce the number of samples maintaining as much spectral variety as possible. Mahalanobis distances $(\mathrm{H})$ for each sample were calculated and samples were grouped according to a neighborhood $\mathrm{H}$ criterion $(\mathrm{NH} \leq 0.6)$. So, 18 groups with different spectral characteristics were created and one sample from every group was selected. These 18 selected samples were used in all the subsequent analyses.

\section{Total phenol extractability determination}

A model wine extraction and an exhaustive extraction were carried out to determine the extractability of total phenols for selected wood samples. For model wine extraction, wood samples were immersed in a model wine hydroalcoholic solution $\left(4 \mathrm{~g} \mathrm{~L}^{-1}\right.$ tartaric acid, $12.5 \%$ ethanol, adjusted at $\mathrm{pH} 3.6$ with $\mathrm{NaOH} 0.5 \mathrm{M}$ ) for a maceration period of $72 \mathrm{~h}$ at room temperature and without agitation. Oak wood shavings were added to the wine-like solution in a $4 \mathrm{~g} \mathrm{~L}^{-1}$ ratio. Then, supernatants were used to obtain extractable total phenolic content. Afterwards, wood samples were freeze-dried and macerated in methanol: water 50:50 (v/v) during $24 \mathrm{~h}$ to obtain an exhaustive extraction of phenolic compounds. Total phenolic content was obtained by the analysis of the model wine and exhaustive supernatants. Total phenol contents were determined using the Folin-Ciocalteau method [38]. Two hundred and fifty microliters of exhaustive or model wine extractions were mixed with $3.75 \mathrm{~mL}$ of sodium carbonate $(20 \% \mathrm{w} / \mathrm{v}), 1.25 \mathrm{~mL}$ of Folin reagent and made up to $25 \mathrm{~mL}$ with ultrapure water. The analyses were performed on an Agilent 8453 UV-visible spectrophotometer (Palo Alto, USA), equipped with diode array detection (DAD), measuring absorbance at $765 \mathrm{~nm}$. Then, extractabilities of each sample were evaluated as the fractions of total phenols extracted by the model wine solution with respect to the exhaustive extraction. Finally, wood samples were sorted according to their phenolic extractability levels expressed as percentages.

As a by-product of model wine and exhaustive extractions, non-extracted material (NEM) was obtained from each wood selected sample. These NEM samples were freezedried and then stored in a desiccator until further use. Control (without extraction process) and NEM selected samples were used in the subsequent analysis. From here on, the term "wood samples" will be used for control samples. Nonextracted material will be specified by the acronym, NEM.

\section{ATR-FTIR data collection}

IR absorption measurements were carried out using a Perkin Elmer Spotlight 400 N FTIR imaging system. The data have been collected using both the ATR mode and Micro-ATR imaging mode. A liquid nitrogen-cooled mercury cadmium telluride (MCT-A) line detector was used.

\section{Data collection using the ATR mode}

ATR spectra were recorded using the Perkin Elmer Spotlight $400 \mathrm{~N}$ Universal Attenuated Total Reflectance (UATR) accessory of the spectrometer, which employs a 9-bounce diamond top plate for this analysis. Spectral data were the result of 8 scans, with a spectral resolution of $4 \mathrm{~cm}^{-1}$ and covering the spectral range between 650 and $4000 \mathrm{~cm}^{-1}$. All samples were measured with a force gauge of 250 units. 6 absorption spectra were collected for each sample. Prior to recording, a background spectrum was also recorded in the absence of any sample and automatically subtracted by the software.

\section{Data collection using the micro ATR imaging mode}

ATR images were recorded with the Perkin Elmer Spotlight 400 N ATR imaging adapter using a germanium crystal 
objective of dimensions $\sim 600 \mu \mathrm{m} \times 600 \mu \mathrm{m}$ placed in direct contact with the sample. Spectral images were acquired covering the spectral range between 750 and $4000 \mathrm{~cm}^{-1}$ with a pixel size of $6.25 \mu \mathrm{m} \times 6.25 \mu \mathrm{m}$, with 4 scan per pixel at a spectral resolution of $8 \mathrm{~cm}^{-1}$. Background measurement was acquired without sample and without contact between the crystal and the support. ATR images were acquired across a $500 \mu \mathrm{m} \times 500 \mu \mathrm{m}$ region of the ATR crystal. The ATR crystal was gently placed in contact with the sample using pressure to ensure good contact.

\section{Raman data collection}

A Horiba Jobin-Yvon LabRAM HR800 spectrometer with an external $300-\mathrm{mW}$ diode laser operating at $785 \mathrm{~nm}$ as source was used throughout this work. For the measurements, $a \times 50$ objective (MPlanN, Olympus) was employed, providing a spatial resolution of $\sim 1 \mu \mathrm{m}$ at the sample. The confocal hole was set at $100 \mu \mathrm{m}$, the specified setting for confocal operation. The system was spectrally calibrated to the $520.7 \mathrm{~cm}^{-1}$ spectral line of silicon. The LabRAM system is a confocal spectrometer that contains two interchangeable gratings (300 and 900 lines per mm, respectively). In the following experiments, the 300 lines per $\mathrm{mm}$ grating was used, providing a spectral dispersion of approximately $1.5 \mathrm{~cm}^{-1}$ per pixel. The detector used was a 16-bit dynamic range Peltier-cooled CCD detector. All spectra were recorded over the spectral range between 200 and $3600 \mathrm{~cm}^{-1}$ and with a spectral resolution of $\sim 0.9-1.6 \mathrm{~cm}^{-1}$. Six spectra were collected for each sample.

\section{Scanning electron microscopy}

Scanning electron microscopy (SEM) analysis was performed to analyze surface topography and porosity using a Hitachi SU $6600 \mathrm{Fe}-\mathrm{SEM}$ instrument. Samples were placed on conductive carbon tabs before being placed in the sample chamber. An accelerating voltage of $2 \mathrm{kV}$, working distance of $30 \mathrm{~mm}$, condenser lens of 21.0 and current of $20 \mu \mathrm{A}$ were used for all samples.

\section{Data analysis}

Samples were sorted into three groups, low, medium and high phenolic extractability levels according to the reference values previously calculated. Wood spectra contain contributions from the chemical content of the sample and physical effects. Therefore, the interpretation of the results obtained from Raman and FTIR spectroscopy requires the pretreatment of the data. A multiplicative scatter correction (MSC) was applied to the ATR-FTIR raw spectra to remove the scattering effects. Win ISI (v1.50) (Infrasoft International, LLC, Port. Matilda, PA, USA, 2000) software was used for this aim. ATR-FTIR images were normalized to adjust for point-to-point variations in absorbance and allow the comparison between samples using the SpectrumIMAGE software. Baseline correction was applied to Raman raw data. This correction was carried out using MATLAB R2017b (The Mathworks, Natik, MA, USA, 2017) and following the algorithm previously described [39]. Asymmetric truncated quadratic was the cost function, which gives the best results to estimate background in Raman spectra of wood samples, and the backgrounds were estimated by a fifth-order polynomial and with thresholds of 0.01 .

\section{Results and discussion}

\section{Total phenol extractability levels}

According to their total phenol extractability levels, wood samples were sorted into three different groups, designated as low, medium and high extractability levels. Table 1 shows the extractability levels of total phenols for the wood samples and the number of samples classified in each group. Moreover, the table details the distribution of the samples of each group in the longitudinal or transversal set. As can be seen, most of the high extractability samples belong to the longitudinal set, while the transversal set consists mainly of low extractability samples.

\section{ATR-FTIR data}

\section{ATR mode}

A typical ATR-FTIR spectrum of raw oak wood is depicted in Fig. 1. Despite the background correction

Table 1 Extractability levels of total phenols for wood samples (means and standard deviations) and distribution of the samples in the longitudinal and transversal set

\begin{tabular}{|c|c|c|c|c|c|}
\hline \multirow[b]{2}{*}{ Samples } & \multirow[b]{2}{*}{$n^{\mathrm{a}}$} & \multicolumn{2}{|c|}{$\begin{array}{l}\text { Total extract- } \\
\text { abilities } \\
\text { (expressed as } \\
\text { percentages) }\end{array}$} & \multicolumn{2}{|l|}{ Cut group } \\
\hline & & Mean & SD & Longitudinal $^{\mathrm{b}}$ & Transversal $^{c}$ \\
\hline All & 18 & 72.23 & 7.55 & 10 & 8 \\
\hline Low & 4 & 62.01 & 3.19 & 1 & 3 \\
\hline Medium & 6 & 70.29 & 2.80 & 2 & 4 \\
\hline High & 8 & 80.02 & 1.97 & 7 & 1 \\
\hline
\end{tabular}

${ }^{a}$ Number of samples

${ }^{\mathrm{b}}$ Samples obtained by shaving the staves in the longitudinal direction of the staves

${ }^{\mathrm{c}}$ Samples obtained by shaving the staves in the transversal direction of the staves 


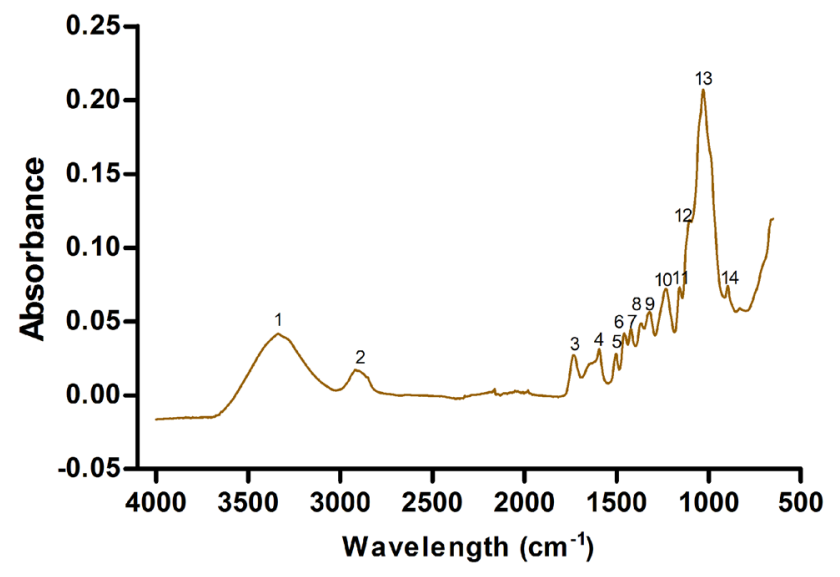

Fig. 1 FT-IR spectrum of raw oak wood

procedure, a negative baseline was consistently returned for all samples in the region $3500-4000 \mathrm{~cm}^{-1}$, perhaps due to a refractive index matching between the sample and crystal in this region. FTIR spectra are characteristics of the chemical composition of the samples and their peaks can be tentatively assigned to specific molecular bonds or functional groups. A hydrogen bonded $(\mathrm{O}-\mathrm{H})$ stretching absorption at $3500-3300 \mathrm{~cm}^{-1}$ (1) and a C-H stretching absorption around $2900 \mathrm{~cm}^{-1}$ (2) are observed. The region between 1800 and $600 \mathrm{~cm}^{-1}$, known as the IR fingerprint region, is the region that provides information relevant to molecular structure by means of many well-defined peaks. The bands at 1594, 1505 and $1235 \mathrm{~cm}^{-1}$ are assigned to characteristic bending or stretching of different groups of lignin. The bands centered at 1455, 1422, 1371, 1155 and 1108 are assigned to characteristic bending or stretching vibrations of different groups for lignin and cellulose [28]. The main characteristic peaks, which are the stretching vibration of $\mathrm{C}=\mathrm{O}$, aromatic and $\mathrm{C}-\mathrm{O}$, are around 1594 , 1505 and $1050 \mathrm{~cm}^{-1}$ [40]. A summary of peak assignments can be found in Table 2. These peaks have been assigned in accordance with available literature [41-45].

Figure $2 \mathrm{a}, \mathrm{b}$ shows the raw average spectra, in the region from 600 to $4000 \mathrm{~cm}^{-1}$, of wood samples designated as (a) low, medium and high extractability (including all longitudinal and transverse samples) and (b) as belonging to the longitudinal or transversal set. In both cases, the different spectra have the same pattern, although with different absorbance intensities in some wavelength regions. MSC spectral pretreatment was then applied to the ATR-FTIR spectra and average spectra were calculated for each wood sample. Afterwards, PCA was applied to this spectral matrix. Using all spectral samples, eight principal components were taken into account and $98.57 \%$ of the spectral variability of the original spectral matrix was explained. Mahalanobis distances for each sample were calculated. The samples were ranked, in this eightdimensional space, according to their Mahalanobis distances $(H)$ and the $H>3$ criterion was applied to look for spectral outliers. No H-outliers were found. Figure 2c, d shows the scatter plots of the wood samples in the space defined by the first and second principal components, which described $57.70 \%$ (PC1) and $21.50 \%$ (PC2) of the variability in the data, respectively. In Fig. 2c, the samples are represented by a color code according to the different levels of extractability. As the figure shows, high and low extractability samples are separated according to PC2, while medium extractability samples overlap the low and high extractability ones. Using this same spectroscopic
Table 2 Main functional groups assigned to the different vibrations present in the ATRFTIR spectra of wood samples

\begin{tabular}{lllc}
\hline $\begin{array}{l}\text { Absorption bands } \\
\left(\mathrm{cm}^{-1}\right)\end{array}$ & Assignment & Component & $\begin{array}{l}\text { Peak refer- } \\
\text { ence (Fig. 1) }\end{array}$ \\
\hline 3300 & $v(\mathrm{O}-\mathrm{H})$ & Polysaccharides, lignin & 1 \\
2900 & $v(\mathrm{CH})$ & Lignin & 2 \\
1730 & $v(\mathrm{C}=\mathrm{O})_{\text {ester }}$ & Lignin, hemicellulose & 3 \\
1594 & $v(\mathrm{C}-\mathrm{C})_{\text {aromatic }}$ & Lignin, phenolics & 4 \\
1505 & $v(\mathrm{C}-\mathrm{C})_{\text {aromatic }}$ & Lignin, phenolics & 5 \\
1455 & $\delta(\mathrm{C}-\mathrm{H})$ & Lignin, polysaccharides & 6 \\
1422 & $\delta(\mathrm{C}-\mathrm{H})$ & Lignin, polysaccharides & 7 \\
1371 & $\delta(\mathrm{C}-\mathrm{H})$ & Cellulose, hemicellulose & 8 \\
1319 & $v(\mathrm{C}-\mathrm{H})$ and $v(\mathrm{C}-\mathrm{O})$ & Cellulose, Syringyl derivates & 9 \\
1235 & $v(\mathrm{C}-\mathrm{O})$ & Lignin, xylan & 10 \\
1155 & $v(\mathrm{C}-\mathrm{O}-\mathrm{C})$ & Cellulose, hemicellulose & 11 \\
1108 & $v(\mathrm{C}-\mathrm{C})_{\text {aromatic }}, \delta(\mathrm{O}-\mathrm{H})$ & Cellulose, hemicellulose, phenolics & 12 \\
1050 & $v(\mathrm{C}-\mathrm{O})$ & Cellulose, hemicellulose & 13 \\
892 & $\delta(\mathrm{C}-\mathrm{H})$ & Cellulose & 14 \\
\hline
\end{tabular}

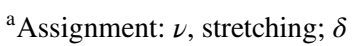



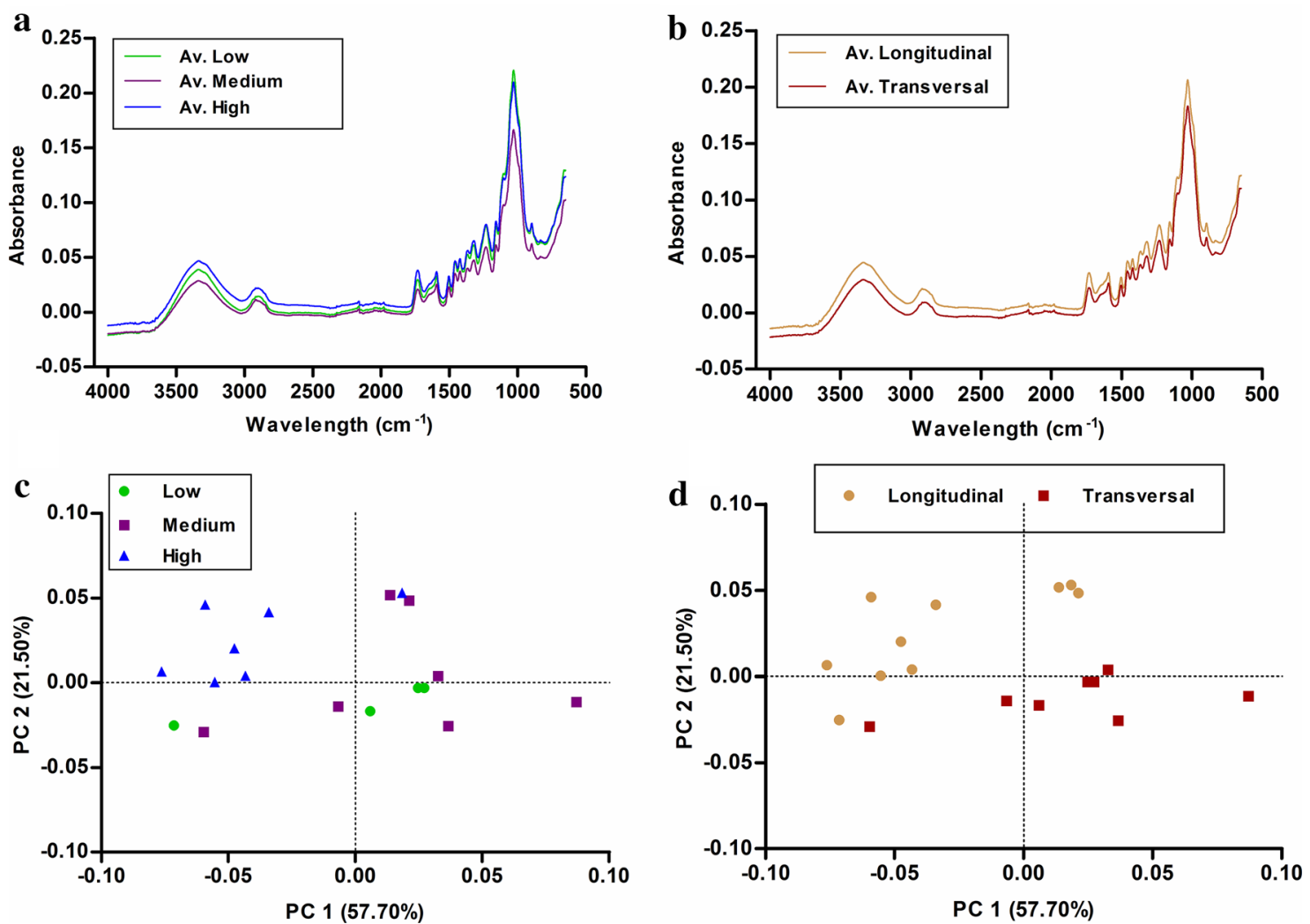

Fig. 2 Raw average spectra of wood samples with low, medium and high extractabilities (a) and belonging to longitudinal and transversal set (b) in the region from 600 to $4000 \mathrm{~cm}^{-1}$. Score plot of the first two principal components obtained in the PCA performed on

technique, samples have been differentiated according to extractability in other samples [36, 37].

In Fig. 2d, the samples have been represented in order to find differences between samples obtained by a cut of the staves in the longitudinal or transversal direction of the fibers. The two samples sets are largely differentiated by PC2.

Figure 3 shows the PC2 loadings and the MSC pre-treated average spectra of wood samples with low and high extractabilities. Although the loading of PC2 indicates a significant baseline contribution, specific spectral features are indicated which may influence the wood phenolic extractability. Positive features, ascribed to the high phenolic content samples, can be seen in the $1500-1800 \mathrm{~cm}^{-1}$ and $2700-3000 \mathrm{~cm}^{-1}$ spectral areas; while negative features, ascribed to the low extractability samples, are observed in the region $1000-1100 \mathrm{~cm}^{-1}$. These features are mainly ascribed to phenolic compounds and lignin (positive features); cellulose and hemicellulose (negative features) (Table 2). Therefore, it may be inferred that high extractability samples are rich in lignin and phenolic compounds, while low extractability samples are rich in polysaccharides. Despite the obvious fact that the phenolic compounds content influences the phenolic

ATR-FTIR spectra recorded from wood samples. The individual data points have been color coded according to the phenolic extractability levels (c) and according to the cut direction of the staves (longitudinal and transversal) (d)

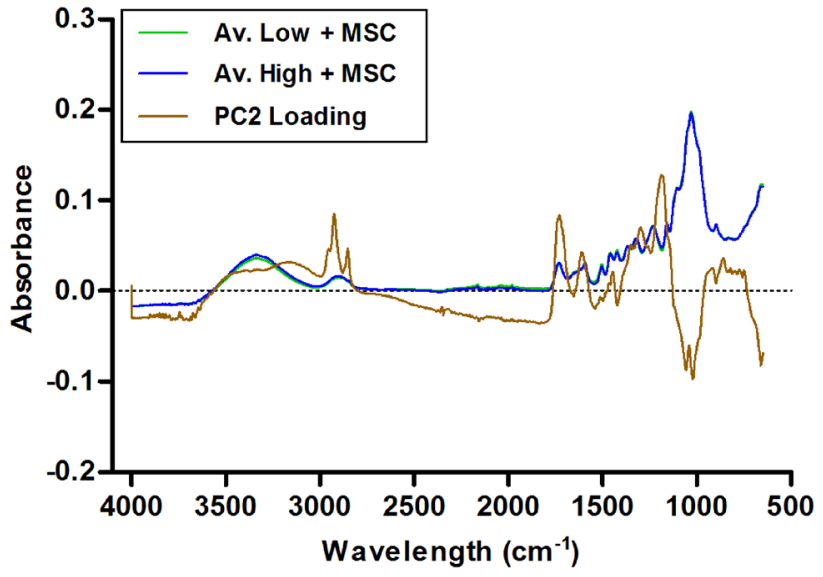

Fig. 3 PC2 loading plot and average MSC pre-treated ATR-FTIR spectra for low and high phenolic extractability wood samples

extractability, the results indicate that phenolic extractability is also influenced by the structure of the wood itself, (i.e., by the ease with which the phenolic compounds can be released from the wood to the medium). This observation 
is supported by the fact that most of the high extractability samples have been obtained by sawing the staves in the longitudinal direction of the fibers, while low extractability samples belong to the transversal set, as can be seen in Table 1. Longitudinal and transversal samples may present the same chemical composition, but differ significantly in structural aspects.

\section{ATR Imaging mode}

To confirm and consolidate the above findings, micro-ATR images of the wood samples were registered, over the spectral range between 750 and $4000 \mathrm{~cm}^{-1}$. After integration of the whole data set, the spectral data were normalized and specific wavenumber ranges of all the spectra were selected using the instrument software. The loadings of the second principal components previously obtained in the PCA of ATR-FTIR data were used for wavelength region selection, because this principal component was responsible for the separation of the samples according to the extractability levels (high and low). The wavenumbers corresponding to higher loadings of this particular principal component were selected as candidates for optimum visualization of structural variations. Based on the results obtained in the previous section, wavenumber regions ascribed to polysaccharides (cellulose, hemicellulose $1000-1100 \mathrm{~cm}^{-1}$ ) and lignin (1500-1800 $\mathrm{cm}^{-1}$ and $2700-3000 \mathrm{~cm}^{-1}$ ) were selected as spectral regions that might influence the wood phenolic extractability and therefore are considered in ATR-FTIR images for interpretation purposes. Figure 4 shows an example of the distribution of the absorbance, integrated over the selected wavenumber ranges, of samples with low and high extractability levels, as a false color image. In general, the absorbance levels for all samples were variable, as indicated by the spread of data points for the samples in Fig. 2c, d. Considering the distribution of cellulose/hemicellulose in the mapped area (Fig. 4a, d), it can be observed that, in general, polysaccharides are present in almost all mapped regions, with the exception of a small region in the high extractability sample. This region could be related to structures such as vessels or cellular lumens in high extractability samples as a consequence of the different cutting direction of the staves to obtain the two sample sets. The spectral ranges of $1500-1800 \mathrm{~cm}^{-1}$ and $2700-3000 \mathrm{~cm}^{-1}$ are ascribed to a combination of lignin and phenolic compounds, and lignin alone, respectively. For both, high and low extractability samples, the spectral distributions of these regions follow a similar pattern, although the $1500-1800 \mathrm{~cm}^{-1}$ absorbances are higher in Fig. 4b, e. Consistent with literature [34, 35], the spatial profile of spectral bands associated with lignin (Fig. 4b, c, e, f) indicate a lower proportion of this compound than polysaccharides in the samples. Areas of higher lignin content seem to belong to the characteristic fibers and rays of wood, structures which are richer in lignin [12, 34].
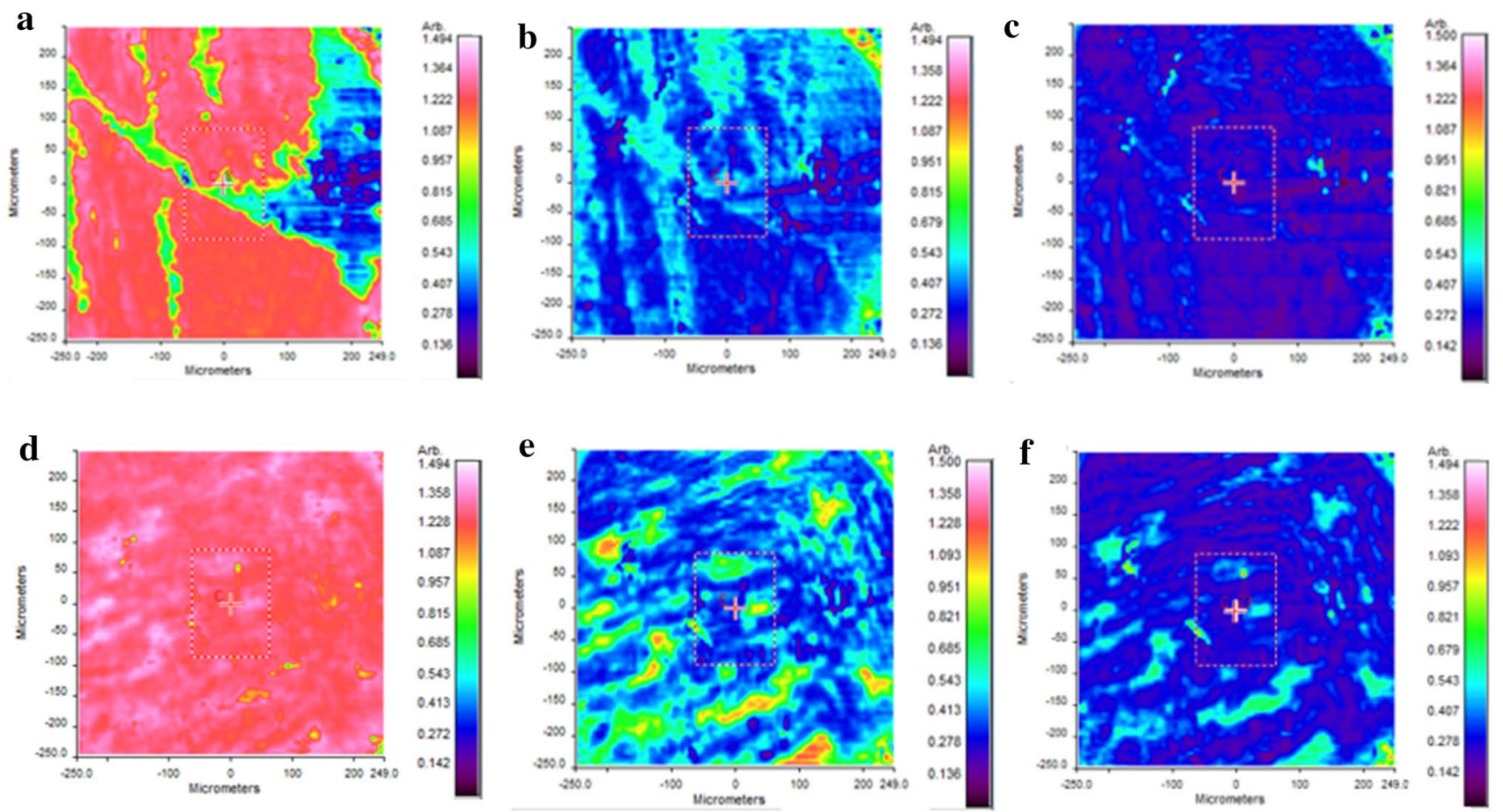

Fig. 4 Distribution of the absorbance of samples with high $(\mathbf{a}, \mathbf{b}, \mathbf{c})$ and low $(\mathbf{d}, \mathbf{e}, \mathbf{f})$ extractabilities levels as a false color image in the selected range of wavenumber: $1000-1100 \mathrm{~cm}^{-1}(\mathbf{a}, \mathbf{d}), 1500-1800 \mathrm{~cm}^{-1}(\mathbf{b}, \mathbf{e})$ and $2700-3000 \mathrm{~cm}^{-1}$ (c, f) 
It is notable that, for all high extractability samples mapped, the regions of maximum absorbance in the spectral range of cellulose/hemicellulose $\left(1000-1100 \mathrm{~cm}^{-1}\right)$ do not coincide with those of maximum absorbance of lignin/ phenolics $\left(1500-1800 \mathrm{~cm}^{-1}\right.$ and $2700-3000 \mathrm{~cm}^{-1}$ ). In contrast, for the low extractability samples, the regions of high absorbance of all spectral ranges are co-incident.

The difference in structural distributions of the constituent components corroborates the proposal that not only the chemical content, but also the structure of the wood samples play a significant role in determining the phenolic extractability.

\section{ATR-FTIR NEM}

ATR-FTIR spectra and images of non-extracted material (NEM) were also recorded and the data were processed following the same procedure used to analyze the control samples. Figure 5a shows the scores of the NEM samples in the space defined by the two first principal components. It can be seen that, after the extraction of the phenolic compounds, it is still possible to observe some degree of separation between low and high extractability samples according to the second principal component. These results support the influence of the wood cell wall structure on the extraction of phenolic compounds. Loadings of PC2 and the MSC pretreated average spectra of NEM samples with low and high extractabilities are represented in Fig. 5b. As in the case of the control samples, peaks ascribed to lignin are strong (negative) in high extractability samples, while those ascribed to cellulose/hemicellulose are prominent (positive) for low extractability samples. It can be seen that the feature related to phenolic compounds which can be seen around $1150 \mathrm{~cm}^{-1}$ in the PC2 loading of the control samples is significantly reduced in the PC2 loadings of the samples obtained after the extraction of the phenolic compounds (NEM samples).
The spectral region of PC2 loadings that show high variations related to lignin and polysaccharides $\left(1000-1100 \mathrm{~cm}^{-1}\right.$, $1500-1700 \mathrm{~cm}^{-1}$ and $2700-3000 \mathrm{~cm}^{-1}$ ) was selected for ATR-FTIR image processing. Similar to the case of the control samples, a high degree of inter-sample variation of absorbance levels is observed. Notably, however, in the high extractability samples, a high degree of correlation of the three wavenumber regions is observed, as shown for one example in Fig. 6. In the NEM samples, phenolic compounds have been extracted and thus, the absorbance of $1500-1700 \mathrm{~cm}^{-1}$ and $2700-3000 \mathrm{~cm}^{-1}$ spectral areas is practically identical.

\section{Raman data}

To confirm and/or complement the findings obtained using ATR-FTIR, Raman spectra of wood samples were collected. Six samples were randomly selected, taking care to select from different extractability levels and quite noisy spectra with several peaks were obtained. Figure 7a shows a typical wood spectrum after the baseline correction. This spectrum shows characteristic Raman peaks for polysaccharides, lignin and phenolic compounds [34, 46-49]. The celluloserelated peaks in the Raman spectra are at 895, 1098, 1125 and $1330 \mathrm{~cm}^{-1}$. In detail, cellulose $\mathrm{HCC}$ and $\mathrm{HCO}$ bending at $895 \mathrm{~cm}^{-1}$, cellulose $\mathrm{CC}$ and $\mathrm{CO}$ stretch at $1098 \mathrm{~cm}^{-1}$, cellulose $\mathrm{CC}$ and $\mathrm{CO}$ stretch; HCC and $\mathrm{HCO}$ bend at $1125 \mathrm{~cm}^{-1}$, cellulose HCC and HCO bend at $1330 \mathrm{~cm}^{-1}$. The feature at $1605 \mathrm{~cm}^{-1}$ is reported to be associated with an aromatic skeletal vibration of lignin and phenolic compounds. This band presents a strong Raman intensity, whereas it is only weakly active in infrared spectroscopy. The large intensity of this peak is in agreement with the presence of phenolic compounds in the samples. One last peak related to lignin $\mathrm{C}=\mathrm{C}$ stretch can be appreciated at $1632 \mathrm{~cm}^{-1}$.
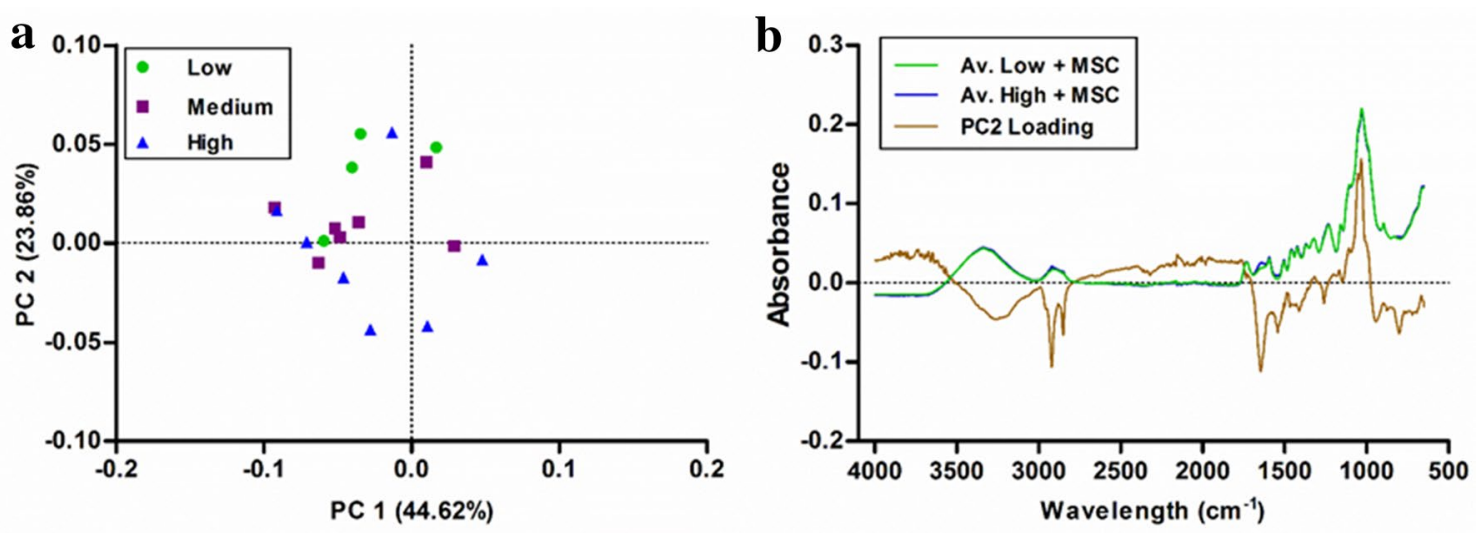

Fig. 5 Score plot of NEM samples in the space defined by PC1 and PC2 codified according to the phenolic extractability levels (a). PC2 loading plot and average MSC pre-treated ATR-FTIR spectra for low and high phenolic extractability NEM samples (b) 

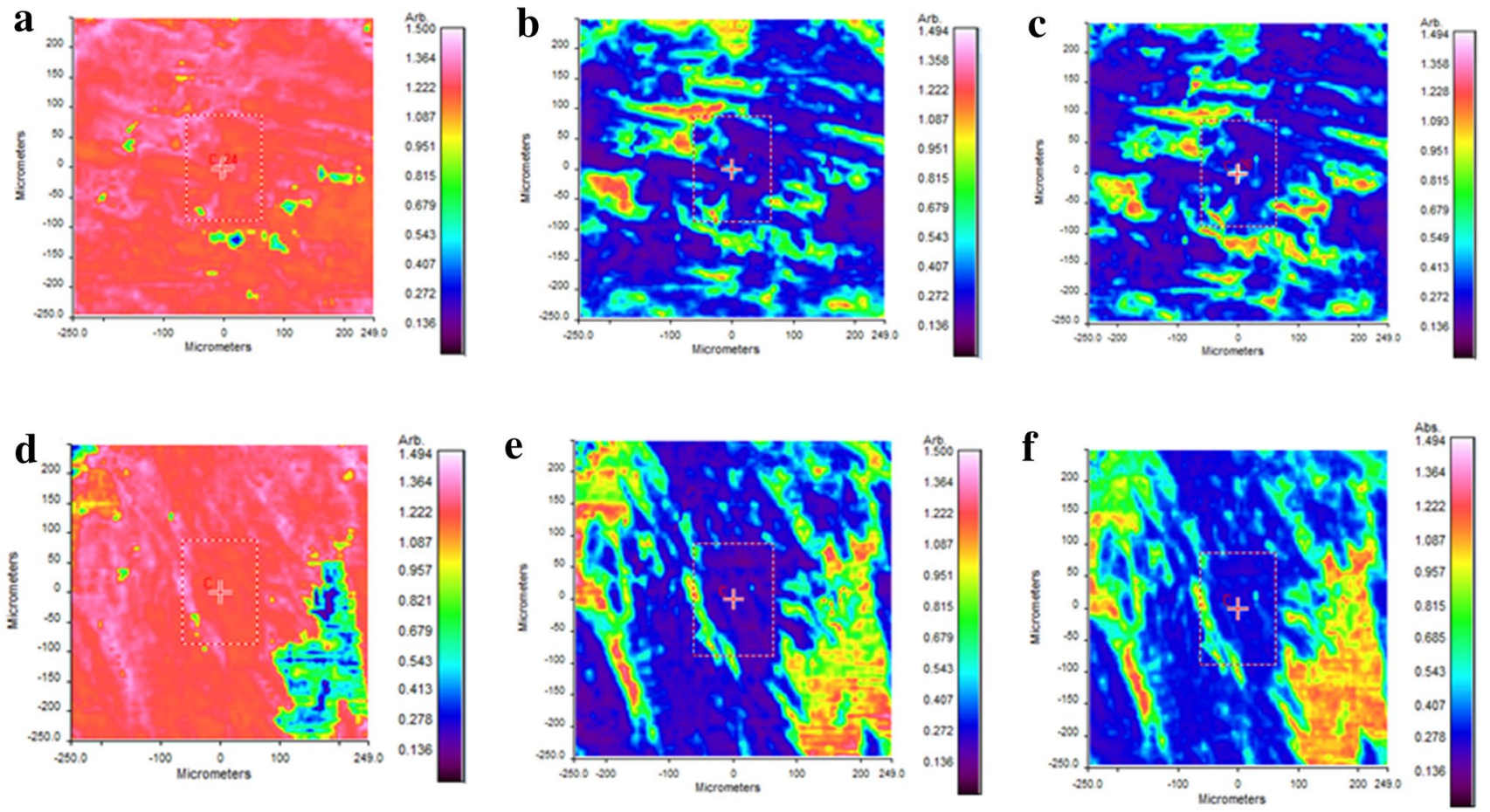

Fig. 6 Distribution of the absorbance of NEM samples with high $(\mathbf{a}, \mathbf{b}, \mathbf{c})$ and low $(\mathbf{d}, \mathbf{e}, \mathbf{f})$ extractabilities levels as a false color image in the selected range of wavenumber: $1000-1100 \mathrm{~cm}^{-1}(\mathbf{a}, \mathbf{d}), 1500-1800 \mathrm{~cm}^{-1}(\mathbf{b}, \mathbf{e})$ and $2700-3000 \mathrm{~cm}^{-1}(\mathbf{c}, \mathbf{f})$

To further examine the results, PCA was performed. Figure $7 \mathrm{~b}$, c shows the scores of the wood samples in the space defined by the first and second principal components, which described $63.28 \%$ (PC1) and $15.60 \%$ (PC2) of the variability in the data. Following the same procedure as in ATR-FTIR data, in the plot $6 \mathrm{~b}$, the color code indicates different extractability levels of the samples; while in the plot $6 c$, it indicates different cutting direction. As in ATR-FTIR results, a slight degree of separation between high and low extractability samples is indicated, in this case according to PC1. However, in this case, medium extractability samples are overlapped with those of low extractability. Regarding the cutting direction, the second principal component provides valuable information, with transversal samples having higher scores than longitudinal ones (Fig. 7c). Therefore, Raman spectroscopy enables confirmation of the linkage between cell wall components and phenolic extractability in wood samples.

\section{Scanning electron microscopy}

After analysis by ATR-FTIR and Raman spectroscopy, wood samples of high and low extractability levels were visualized by scanning electron microscopy (SEM) to obtain a more complete understanding about their ultrastructure (Fig. 8). Micrographs show morphological differences between the structure of these two groups of samples that could be related to the different phenolic extractability levels. According to what can be seen in the images, samples of high extractability have more cavities (cell lumens, intercellular spaces) in view. This behavior could be probably explained by the different cuts to which the staves have been subjected to obtain the samples (longitudinal and transversal). In this sense, it has to be taken into consideration that most of the high extractability samples belong to the longitudinal set, while the transversal set consists mainly of low extractability samples, as can be seen in Table 1. Taking into account that compounds constituting the extractable fraction, and therefore phenolic compounds, can be mixed with the polymers in the cell wall and also as inclusions in the cell lumens, the processing of the staves in the longitudinal direction of the staves could facilitate the transfer of phenolic compounds from wood to the medium.

\section{Conclusion}

ATR-FTIR and Raman spectroscopy provided complementary information about the composition and structure of wood and have been shown to be useful to relate the more important spectral features to phenolic extractability levels of wood samples. These techniques confirmed that wood phenolic extractability is influenced by the cell wall composition (cellulose, hemicellulose and lignin). ATR-FTIR 

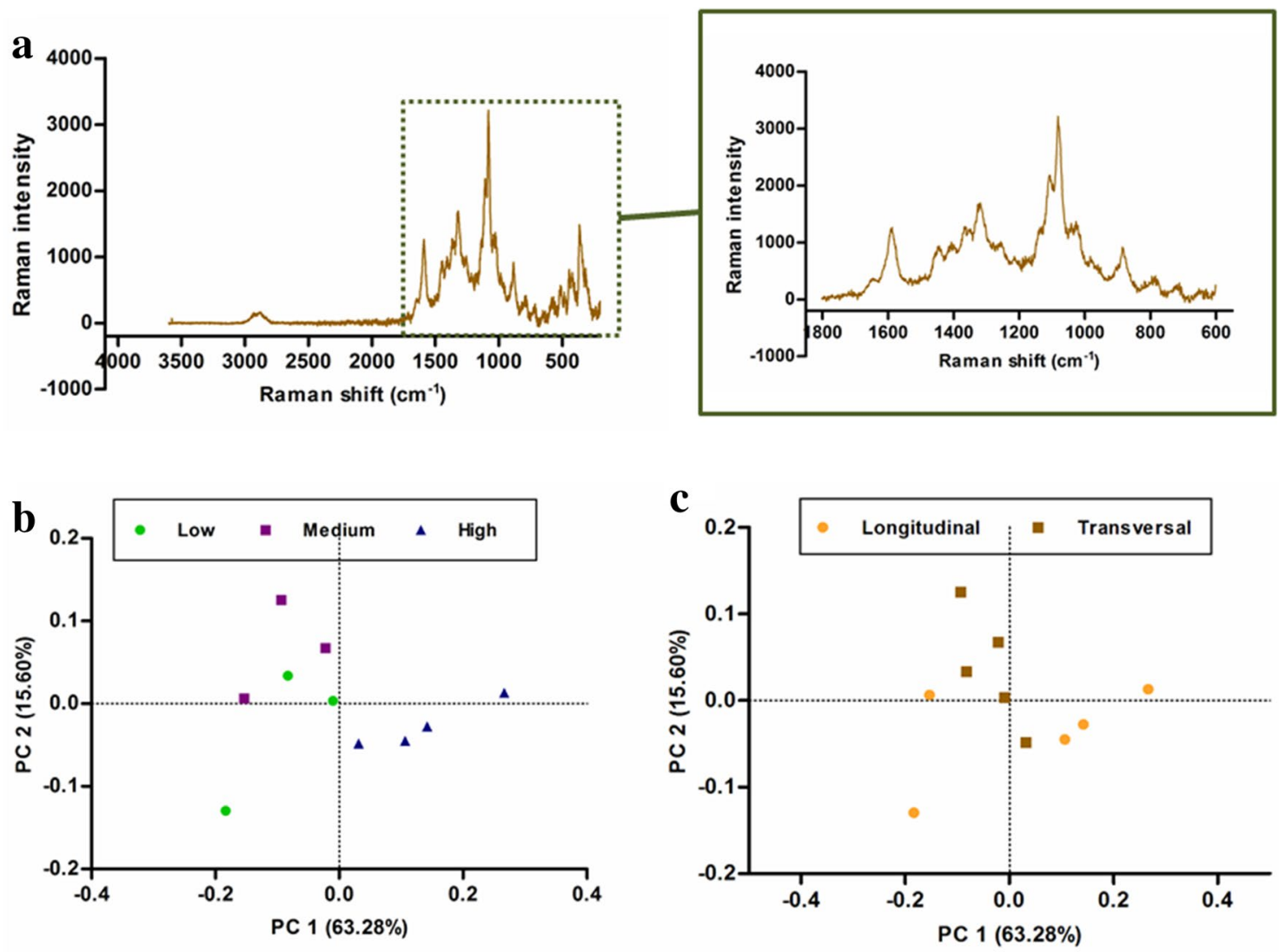

Fig. 7 Baseline corrected Raman spectrum for a wood sample in the region from 200 to $4000 \mathrm{~cm}^{-1}$ and $600-1800 \mathrm{~cm}^{-1}$ (a). Score plot of the first two principal components obtained in the PCA performed on Raman spectra recorded from wood samples. The individual data

points have been color coded according to the phenolic extractability levels (b) and according to the cut direction of the staves (longitudinal and transversal) $(\mathbf{c})$
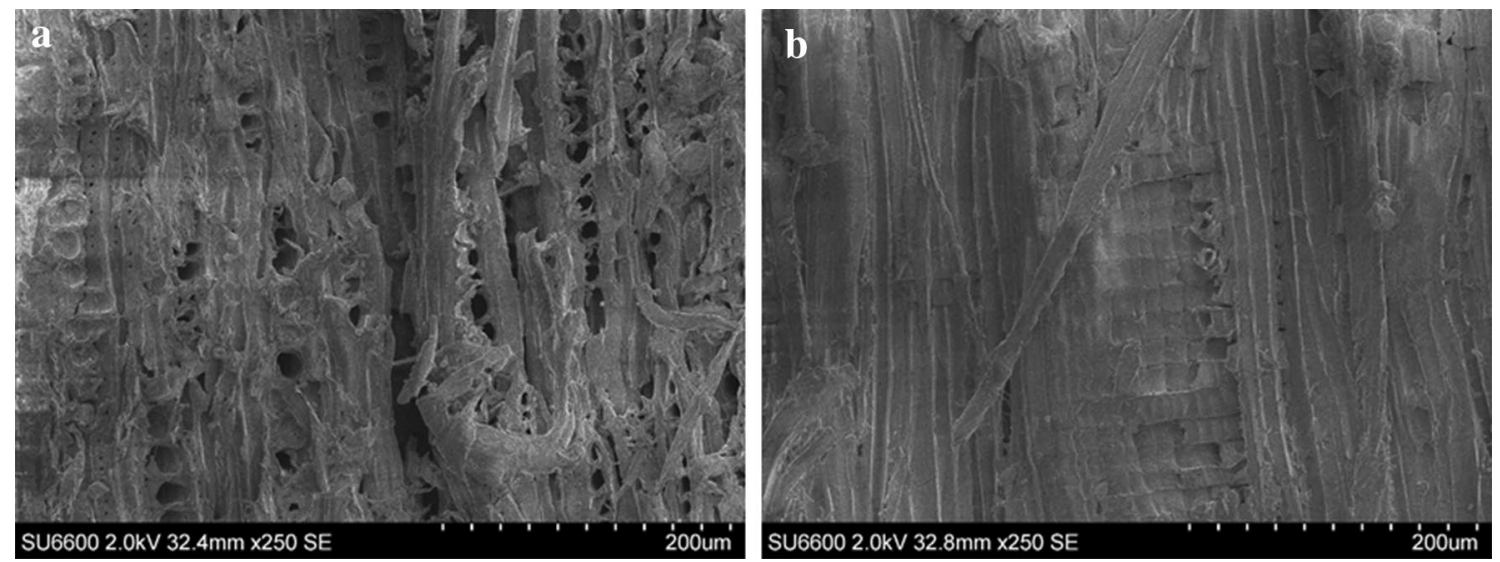

Fig. 8 Scanning electron microscopy (SEM) of wood samples with high (a) and low (b) extractability levels

image spectroscopy has been successfully used to investigate the distribution of lignin and cellulose/hemicellulose. In general, the observed distributions for polysaccharides and lignin are in agreement with the data reported in the literature and confirm that the structure of the wood samples play a significant role in determining the phenolic extractability. Scanning electron microscopy provided valuable complementary information that supports the relationship 
between the structure of the wood and phenolic extractability levels.

Acknowledgements This work was supported by the Spanish MINECO [AGL2017-84793-C2] and Universidad de Sevilla [VPPIII.2, VPPI-II.4, VIPPI-EEBB-PIF 2017].

The authors thank the technical staff of Biology Service [Servicios Generales de Investigación (SGI), Universidad de Sevilla]. They also thank Tonelería Salas S.L. (Bollulos Par del Condado, Huelva, Spain) for supplying the cooperage byproduct samples.

\section{Compliance with ethical standards}

Conflict of interest The authors declare that they have no conflict of interest.

Compliance with ethics requirements This article does not contain any studies with animal or human subjects.

\section{References}

1. Gordillo B, Rodriguez-Pulido FJ, Mateus N, Escudero-Gilete ML, Gonzalez-Miret ML, Heredia FJ, de Freitas V (2012) Application of LC-MS and tristimulus colorimetry to assess the ageing aptitude of Syrah wine in the Condado de Huelva D.O. (Spain), a typical warm climate region. Anal Chim Acta 732:162-171

2. Mira de Orduña R (2010) Climate change associated effects on grape and wine quality and production. Food Res Int 43:1844-1855

3. Mori K, Sugaya S, Gemma H (2005) Decreased anthocyanin biosynthesis in grape berries grown under elevated night temperature condition. Sci Hortic-Amsterdam 105:319-330

4. Boulton R (2001) The copigmentation of anthocyanins and its role in the color of red wines. A critical review. Am J Enol Vitic 52:67-87

5. Bautista-Ortín AB, Lencina AG, Cano-López M, Pardo-Mínguez F, López-Roca JM, Gómez-Plaza E (2008) The use of oak chips during the ageing of a red wine in stainless steel tanks or used barrels: effect of the contact time and size of the oak chips on aroma compounds. Aust J Grape Wine Res 14:63-70

6. Gordillo B, Baca-Bocanegra B, Rodríguez-Pulido FJ, GonzalezMiret ML, García Estévez I, Quijada-Morin N, Heredia FJ, Escribano-Bailón MT (2016) Optimisation of an oak chips-grape mix maceration process. Influence of chip dose and maceration time. Food Chem 206:249-259

7. Eriksson K-EL, Blanchette RE, Ander P (1990) Microbial and enzymatic degradation of wood and wood components. Springer, Berlin

8. Morrell JJ, Gartner BL (1998) Wood as a material. Bruce, A. \& Palfreyman, J.W., London

9. Del Álamo Sanza M, Nevares Domínguez I (2006) Wine aging in bottle from artificial systems (staves and chips) and oak woods. Anal Chim Acta 563:255-263

10. Fernández de Simón B, Cadahía E, Del Álamo Sanza M, Nevares I (2010) Effect of size, seasoning and toasting in the volatile compounds in toasted oak wood and in a red wine treated with them. Anal Chim Acta 660:211-220

11. Frangipane MT, Santis DD, Ceccarelli A (2007) Influence of oak woods of different geographical origins on quality of wines aged in barriques and using oak chips. Food Chem 103:46-54

12. Colares CJG, Pastore TCM, Coradin VTR, Marques LF, Moreira ACO, Alexandrino GL, Poppi RJ, Braga JWB (2016) Near infrared hyperspectral imaging and MCR-ALS applied for mapping chemical composition of the wood specie Swietenia macrophylla King (Mahogany) at microscopic level. Microchem J 124:356-363

13. Masson G, Moutounet M, Puech JL (1995) Ellagitannin content of oak wood as a function of species and of sampling position in the tree. Am J Enol Vitic 46:262-268

14. Fournand D, Vicens A, Sidhoum L, Souquet JM, Moutounet M, Cheynier V (2006) Accumulation and extractability of grape skin tannins and anthocyanins at different advanced physiological stages. J Agric Food Chem 54:7331-7338

15. Hernandez-Hierro JM, Quijada-Morin N, Martinez-Lapuente L, Guadalupe Z, Ayestaran B, Rivas-Gonzalo JC, EscribanoBailon MT (2014) Relationship between skin cell wall composition and anthocyanin extractability of Vitis vinifera $\mathrm{L}$. cv. Tempranillo at different grape ripeness degree. Food Chem 146:41-47

16. Hernandez-Hierro JM, Quijada-Morin N, Rivas-Gonzalo JC, Escribano-Bailon MT (2012) Influence of the physiological stage and the content of soluble solids on the anthocyanin extractability of Vitis vinifera L. cv. Tempranillo grapes. Anal Chim Acta 732:26-32

17. Quijada-Morín N, Hernández-Hierro JM, Rivas-Gonzalo JC, Escribano-Bailón MT (2015) Extractability of low molecular mass flavanols and flavonols from red grape skins. Relationship to cell wall composition at different ripeness stages. J Agric Food Chem 63:7654-7662

18. Torchio F, Cagnasso E, Gerbi V, Rolle L (2010) Mechanical properties, phenolic composition and extractability indices of Barbera grapes of different soluble solids contents from several growing areas. Anal Chim Acta 660:183-189

19. Zouid I, Siret R, Jourjon F, Mehinagic E, Rolle L (2013) Impact of grapes heterogeneity according to sugar level on both physical and mechanical merries properties and their anthocyanins extractability at harvest. J Texture Stud 44:95-103

20. González-Manzano S, Rivas-Gonzalo JC, Santos-Buelga C (2004) Extraction of flavan-3-ols from grape seed and skin into wine using simulated maceration. Anal Chim Acta 513:283-289

21. Byrne HJ, Ostrowska MK, Nawaz H, Dorney J, Meade DA, Bonnier F, Lyng MF (2014) Vibrational spectroscopy: disease diagnostics and beyond. In: Baranska M (ed) Optical spectroscopy and computational methods in biology and medicine. Springer Netherlands, Dordrecht, pp 355-399. https://doi. org/10.1007/978-94-007-7832-0_13

22. Byrne HJ, Sockalingum GD, Stone N (2011) Chapter 4 Raman microscopy: complement or competitor? In: Moss D (ed) Biomedical applications of synchrotron infrared microspectroscopy: a practical approach. The Royal Society of Chemistry, Karlsruhe, Germany, pp 105-143. https://doi.org/10.1039/9781849731 997-00105

23. Baca-Bocanegra B, Nogales-Bueno J, Hernandez-Hierro JM, Heredia FJ (2018) Evaluation of extractable polyphenols released to wine from cooperage byproduct by near infrared hyperspectral imaging. Food Chem 244:206-212

24. Giordanengo T, Charpentier JP, Boizot N, Roussel S, Roger JM, Chaix G, Robin C, Mourey N (2009) Oakscan: procédé de mesure rapide et non destructif des polyphénols du bois de chêne de tonnellerie. Revue française d'Oenologie 234:10-15

25. Zahri S, Moubarik A, Charrier F, Chaix G, Bailleres H, Nepveu G, Charrier B (2008) Quantitative assessment of total phenol contents of European oak (Quercus petraea and Quercus robur) by diffuse reflectance NIR spectroscopy on solid wood surfaces. Holzforschung 62:679-687

26. Baca-Bocanegra B, Nogales-Bueno J, García-Estévez I, Escribano-Bailón MT, Hernández-Hierro JM, Heredia FJ (2019) Screening of wine extractable total phenolic and ellagitannin contents 
in revalorized cooperage by-products: evaluation by micro-NIRS technology. Food Bioproc Tech 12:477-485

27. Bokobza L (1998) Near infrared spectroscopy. J Near Infrared Spectrosc 6:3-17

28. Chen H, Ferrari C, Angiuli M, Yao J, Raspi C, Bramanti E (2010) Qualitative and quantitative analysis of wood samples by Fourier transform infrared spectroscopy and multivariate analysis. Carbohydr Polym 82:772-778

29. Jaaskelainen AS, Nuopponen M, Axelsson P, Tenhunen M, Loija M, Vuorinen T (2003) Determination of lignin distribution in pulps by FTIR ATR spectroscopy. J Pulp Pap Sci 29:328-331

30. Traore M, Kaal J, Cortizas AM (2016) Application of FTIR spectroscopy to the characterization of archeological wood. Spectrochim Acta Part A 153:63-70

31. Edwards HGM, Cappa de Oliveira LF, Nesbitt M (2003) Fouriertransform Raman characterization of brazilwood trees and substitutes. Analyst 128:82-87

32. Gerasimov VA, Gurovich AM, Kostrin DK, Selivanov LM, Simon VA, Stuchenkov AB, Paltcev AV, Uhov AA (2016) Raman spectroscopy for identification of wood species. J Phys Conf Ser 741:012131. https://doi.org/10.1088/1742-6596/741/1/012131

33. Evans PA (1991) Differentiating hard from soft woods using fourier-transform infrared and fourier-transform raman-spectroscopy. Spectrochim Acta Part A 47:1441-1447

34. Colares CJG, Pastore TCM, Coradin VTR, Camargos JAA, Moreira ACO, Rubim JC, Braga JWB (2015) Exploratory analysis of the distribution of lignin and cellulose in woods by raman imaging and chemometrics. J Braz Chem Soc 26:1297-1305

35. Sun L, Simmons BA, Singh S (2011) Understanding tissue specific compositions of bioenergy feedstocks through hyperspectral raman imaging. Biotechnol Bioeng 108:286-295

36. Nogales-Bueno J, Baca-Bocanegra B, Rooney A, HernandezHierro JM, Byrne HJ, Heredia FJ (2017) Study of phenolic extractability in grape seeds by means of ATR-FTIR and Raman spectroscopy. Food Chem 232:602-609

37. Nogales-Bueno J, Baca-Bocanegra B, Rooney A, HernandezHierro JM, Jose Heredia F, Byrne HJ (2017) Linking ATR-FTIR and Raman features to phenolic extractability and other attributes in grape skin. Talanta 167:44-50

38. Singleton VL, Rossi JA (1965) Colorimetry of total phenolics with phosphomolybdic-phosphotungstic acid reagents. Am J Enol Vitic $16: 144-158$

39. Mazet V, Carteret C, Brie D, Idier J, Humbert B (2005) Background removal from spectra by designing and minimising a non-quadratic cost function. Chemometrics Intell Lab Syst 76:121-133

40. Popescu C-M, Singurel G, Popescu M-C, Vasile C, Argyropoulos DS, Willfor S (2009) Vibrational spectroscopy and X-ray diffraction methods to establish the differences between hardwood and softwood. Carbohydr Polym 77:851-857

41. Faix O (1992) Fourier transform infrared spectroscopy. In: Lin SY, Dence CW (eds) Methods in lignin chemistry. Springer, Berlin, pp 83-109. https://doi.org/10.1007/978-3-642-74065-7_7

42. Karim M, Daryaei MG, Torkaman J, Oladi R, Ghanbary MAT, Bari E (2016) In vivo investigation of chemical alteration in oak wood decayed by Pleurotus ostreatus. Int Biodeterior Biodegrad 108:127-132

43. Pandey KK, Pitman AJ (2003) FTIR studies of the changes in wood chemistry following decay by brown-rot and white-rot fungi. Int Biodeterior Biodegrad 52:151-160

44. Pandey KK, Theagarajan KS (1997) Analysis of wood surfaces and ground wood by diffuse reflectance (DRIFT) and photoacoustic (PAS) Fourier transform infrared spectroscopic techniques. Holz Roh Werkst 55:383-390

45. Schultz TP, Glasser WG (1986) Quantitative structural analysis of lignin by diffuse reflectance Fourier transform spectrometry. Holzforschung 40:37-44

46. Agarwal UP (2014) 1064 nm FT-Raman spectroscopy for investigations of plant cell walls and other biomass materials. Front Plant Sci 5:490

47. Agarwal UP, McSweeny JD, Ralph SA (2011) FT-Raman investigation of milled-wood lignins: softwood, hardwood, and chemically modified black spruce lignins. J Wood Chem Technol 31:324-344

48. Jason SL, Emily AS (2012) Characterization of woody and herbaceous biomasses lignin composition with $1064 \mathrm{~nm}$ dispersive multichannel Raman spectroscopy. Appl Spectrosc 66:903-910

49. Larsen KL, Barsberg S (2010) Theoretical and Raman spectroscopic studies of phenolic lignin model monomers. J Phys Chem B 114:8009-8021

Publisher's Note Springer Nature remains neutral with regard to jurisdictional claims in published maps and institutional affiliations. 